\title{
IN TYPE 2 DIABETES MELLITUS
}

\section{Ahmet Kaya ${ }^{1}$, Mustafa Kulaksizoglu, ${ }^{1}$ Hatice Uğurlu ${ }^{2}$}

1. Necmettin Erbakan University, Meram Medical Faculty, Division of Endocrinology

2. Necmettin Erbakan University, Meram Medical Faculty, Physical Rehabilitation Clinic

\section{INTRODUCTION}

Lifestyle intervention is the first step in diabetes treatment. Medical nutrition therapy and exercise are effective as oral antidiabetics and/or insulin treatment and must be in combination with pharmacological intervention. We aimed to study the effect of lifestyle intervention in obese type 2 diabetics using insulin.

\section{METHODS}

Patients above BMI $>30 \mathrm{~kg} / \mathrm{m}^{2}$, and using more than $>60$ iu insulin per day were enrolled in the study. Their daily calorie requirments were calculated and medical therapy were arranged. In collabaration with Physical Rehabilatation Clinic, patients were ordered to do physical exercises in the hospital. Before the therapy; patients were monitorised in terms of ECG and blood pressure. Maximum heart rate was calculated and 60-80\% of it was calibrated during the exercise. Bicyle warm up for 5 minutes, 20 minutes of active exercise, 5 minutes of cooling was done during the exercise for 20 consecutive days. After discharge from hospital, patients were told to do active exercise for at least 45 minutes every other day. After 6 months, weight, BMI, A1c changes and daily insulin doses were compared.

\section{RESULTS}

There were 21 females (64\%) 12 males (36\%), mean ages were $60.52 \pm 7.45$ years. After six months, mean weight loss was $8.44 \pm 1.22 \mathrm{kgs}(\mathrm{p}=0.002)$, mean BMI decrease was $1.45 \pm 0.71 \mathrm{~kg} / \mathrm{m}^{2}(\mathrm{p}=0.49)$, mean A1c decrease was $2.36 \pm 1.68 \%$ $(\mathrm{p}=0.001)$ and mean daily insulin dose reduction were $24.18 \pm 13.96 \mathrm{iu}(\mathrm{p}=0.001)$.

\section{CONCLUSION}

It should be kept in mind that, unnecessary high daily insulin doses could be the reason for poor glycemic control and obesity especially in patients who are obese and have high A1c levels. Lifestyle intervention is the first and maybe the most effective treatment for obesity and insulin dose reduction, so patients must be motivated and should be followed up regularly. 